\title{
Uma proposta em Saúde do Trabalhador com portadores de LER/DORT: Grupos de Ação Solidária ${ }^{1}$
}

\author{
Maria da Graça Hoefel ${ }^{2}$, Maria da Graça Jacques ${ }^{3}$, Mayte Raya Amazarray ${ }^{4}$, \\ Jussara Maria Rosa Mendes ${ }^{5}$ e Jacéia Aguilar Net $z^{6}$
}

\begin{abstract}
O presente artigo descreve a constituição dos Grupos de Ação Solidária, apresentando suas características e pressupostos, como uma alternativa de atuação em Saúde do Trabalhador voltada para a transformação social para além da noção do dispositivo grupal como tratamento complementar para portadores de LER/DORT. A metodologia de trabalho é determinada a partir de um "emergente grupal", de tal modo que quando uma "situação problema" é apresentada, promove-se a sua análise coletiva com base nas experiências e vivências dos membros dos grupos e sistematizam-se os conhecimentos visando a busca de soluções e a proposição de ações de intervenção. Além disso ao avaliar a ação realizada coletivamente é possivel discutir a experiência vivida assim como os sentimentos associados (medo, sofrimento, prazer) onde a resignificação do trabalho é construida. Tal metodologia tem o objetivo de desenvolver a consciência crítica, abrindo espaço para o resgate do espaço público, a reconstrução da cidadania, o engajamento social e a construção de laços solidários. Assim, o papel desses grupos tem sido o de promover uma redefinição dos comportamentos de dependência e passividade, permitindo a apropriação de um conhecimento coletivamente construído e a aquisição de uma outra postura frente às situações associadas ao adoecimento do trabalho.
\end{abstract}

Palavras-chave: Grupos de Ação Solidária, LER/DORT, Saúde do Trabalhador.

\section{Introdução}

\footnotetext{
A s pesquisas que tratam sobre as dimensões psicossociais da LER/DORT $^{7}$ já se encontram consolidadas no Brasil, sobretudo no que se refere à necessidade de ações terapêuticas abrangentes e multidisciplinares. A sintomatologia, a incapacidade e o sofrimento dos portadores de LER/DORT têm causas e conseqüências socialmente

${ }^{1}$ Agradecemos a participação da psicóloga Silvana de Oliveira e da assistente aocial Elaine Engel Nunes na elaboração deste trabalho.

${ }^{2}$ Médica, Doutora em Sociologia, assessora técnica da Coordenação da Saúde do Trabalhador (COSAT) do Ministério da Saúde, pesquisadora do Laboratório de Psicobiologia do Trabalho da Universidade de Brasília.

${ }^{3}$ Psicóloga, Doutora em Educação, Professora do Pós-Graduação em Psicologia Social e Institucional da Universidade Federal do Rio Grande do Sul.

${ }^{4}$ Psicóloga, Mestre em Psicologia Social e Institucional pela Universidade Federal do Rio Grande do Sul.

${ }^{5}$ Assistente social, Doutora em Serviço Social, Diretora da Faculdade de Serviço Social da Pontifícia Universidade Católica do Rio Grande do Sul.

${ }^{6}$ Educadora Física, Mestranda em Serviço Social pela Pontifícia Universidade Católica do Rio Grande do Sul.

${ }^{7}$ LER/DORT consiste em um conjunto de afecções que acometem músculos, faces musculares, tegumentos, tendões, ligamentos, articulações, nervos e vasos sanguíneos e que têm origem ocupacional (Maeno, 2003).
} 
engendradas que não podem ser desconsideradas. Assim, as condutas terapêuticas propostas necessitam de uma abrangência para além da indicação de prescrições circunscritas ao uso de medicamentos e exercícios físicos e fisioterápicos.

Diversos autores (Hoefel, Mérola \& Bianchesi, 2003; Merlo, Jacques \& Hoefel, 2001; Lima \& Oliveira, 1995; Sato, Araújo, Udihara, Franco, Nicotera, Daldon, Settimi \& Silvestre, 1993, entre outros) propõem a constituição de grupos com portadores de LER/DORT como recurso de tratamento e de pesquisa. Os resultados dessas propostas têm demonstrado que a matriz que individualiza e culpabiliza o trabalhador na compreensão do adoecimento ocupa um menor espaço, bem como se constata a elaboração de estratégias de enfrentamento como modos de diminuir a dor, a desesperança e a depressão que são concomitantes à doença.

As atividades com grupos contêm um potencial que permite a proposição de objetivos que não se restringem a uma proposta terapêutica circunscrita à sintomatologia incapacitante decorrente da LER/DORT. Atividades com grupos podem solidificar laços de solidariedade e promover a construção de uma consciência crítica e da cidadania capazes de ensejar ações de transformação social. Segundo Sandoval (1994), a cidadania é um fenômeno psicossocial concretizado no cotidiano compartilhado. Ao compartilhar experiências comuns, é possível a construção de ações coletivas de preservação de direitos humanos fundamentais, como o direito à integridade física.

Com base no potencial do espaço grupal, constituíram-se os chamados Grupos de Ação Solidária, envolvendo portadores de LER/DORT, como alternativa de engajamento social, de resistência e de proposição de ações capazes de promover mudanças nas situações de trabalho. Assim, espera-se contribuir na reversão do quadro epidêmico hoje característico desta patologia laboral. ${ }^{8}$

Segundo Giddens (2002), a vida social moderna empobrece a ação individual, mas favorece a apropriação de novas possibilidades; ela é alienante, mas ao mesmo tempo, de maneira característica, os homens reagem contra as circunstâncias sociais que consideram opressivas. $\mathrm{O}$ mundo não se constitui como um ambiente impermeável que resiste à intervenção do humano. Nesse sentido, o trabalho com os Grupos de Ação Solidária busca construir, através da participação dos portadores de LER/DORT, um engajamento com o mundo social exterior e a não aceitação da "retirada de cena" decorrente do adoecimento e do conseqüente afastamento do mundo do trabalho.

Este texto descreve a constituição desses grupos, suas características e seus pressupostos como alternativas de atuação social para além de seu objetivo como tratamento complementar para portadores de LER/DORT. Descreve-se o caso que vem ocorrendo em Porto Alegre e algumas ações concretas daí derivadas.

\section{Como são os Grupos de Ação Solidária e quem são seus participantes}

Participam dos Grupos de Ação Solidária portadores de LER/DORT oriundos de diversas categorias profissionais, com diferentes patologias incluídas nessa classificação,

\footnotetext{
${ }^{8}$ Estudos realizados nos Estados Unidos apontam que cerca de 65\% de todas as patologias registradas como ocupacionais são de LER/DORT. No Brasil, segundo os dados disponíveis pelo INSS, as LER/DORT representam 80\% dos diagnósticos que resultam em concessão de auxílio-acidente ou aposentadoria por invalidez, motivadas por doenças do trabalho. (Ministério da Saúde, 2001).
} 
geralmente em estágio avançado da doença, em que, aos sintomas da dor crônica, somam-se a incapacidade para o trabalho e uma série de perdas físicas, sociais, afetivas e familiares decorrentes. As mulheres representam cerca de $80 \%$ dessa população e, de modo geral, possuem baixa qualificação profissional. Essas pessoas estão, na sua maioria, afastadas do trabalho por Auxílio-Doença por Acidente de Trabalho ou são aposentadas por invalidez. São em geral trabalhadores do setor bancário e do setor metalúrgico; muitos são oriundos de instituições bancárias privatizadas.

O afastamento do trabalho agrava a difícil situação econômica desses trabalhadores. Estão expostos, ainda, à discriminação no trabalho, na família, nos serviços de saúde e nas perícias médicas. É importante referir que tais afecções têm como principal característica uma origem multifatorial e a queixa mais prevalente é a dor. Os sintomas são mais importantes do que as alterações nos exames médicos e, na grande maioria das vezes, não existe comprovação através de exames complementares, tendo em vista a invisibilidade orgânica dessas patologias. Nesse sentido, o diagnóstico está muito mais centrado no relato subjetivo da dor. Constata-se que nem sempre as queixas têm crédito, sendo comuns atitudes de desconfiança por parte de vários segmentos sociais sobre a veracidade da doença.

É comum entre os profissionais que tratam desses trabalhadores portadores de LER/DORT, ao examinarem o processo saúde-enfermidade-trabalho de seus pacientes, não visualizarem na organização do trabalho e nas condições laborais - que não se adaptam às características anátomo-fisiológicas dos trabalhadores - os determinantes para o adoecimento, contribuindo para uma postura de culpabilização e de responsabilização dos trabalhadores pela doença. Explicações psicológicas (propensão individual) e morais (fraqueza, falta de vontade) são recorrentes, reforçadas por uma longa tradição de estudos e pesquisas que focalizam no trabalhador as explicações para os acidentes e para as doenças ocupacionais.

Entretanto, esses trabalhadores sabem o que os fez adoecer e sabem identificar os riscos. $\mathrm{Na}$ categoria dos bancários, existem pesquisas ${ }^{9}$ identificando que até $95 \%$ dos trabalhadores sabem o que é LER/DORT e como se dá o processo de adoecimento.

A grande maioria dos portadores de LER/DORT apresenta uma história laboral de resignação e de trabalho com dor. Frente à visão hegemônica das empresas e dos serviços médicos e previdenciários que consideram os trabalhadores com dor osteomuscular como "fracos", "susceptíveis" ou "simuladores", tais indivíduos persistem trabalhando apesar da sintomatologia existente e apenas se afastam quando apresentam um elevado grau de cronicidade, recidivância e incapacidade.

Além disso, é comum aos portadores de LER/DORT se submeterem a inúmeros tratamentos, que, em geral, são de caráter individual e com resultados pouco satisfatórios. A história da assistência médica buscada por esses trabalhadores tem sido a passagem por um grande número de especialistas e por tratamentos os mais diversos. $\mathrm{O}$ desconhecimento da doença e de suas origens por parte de muitos técnicos da área da saúde (Ruiz, 2003) e o "especialismo" têm contribuído para a cronificação dos casos.

Todas essas circunstâncias que cercam os portadores de LER/DORT impõem-lhes um intenso sofrimento, sendo comum uma postura queixosa, resignada e passiva frente à doença e frente ao cotidiano de vida. Tais características estão também presentes nos participantes dos Grupos de Ação Solidária; com o objetivo de desenvolver a auto-reflixidade e o necessário engajamento nas ações do mundo real é que foi constituída a proposta.

\footnotetext{
9 a) Pesquisa realizada pela Federação dos Bancários do Rio Grande do Sul, Censo Bancário: Avaliação da Saúde dos Bancários no Rio Grande do Sul; b) Trabalho de conclusão do Curso de Especialização em Medicina do Trabalho da UFRGS: Uma abordagem socioeconômica do Fenômeno LER/DORT em População de Bancários de Porto Alegre (Luzzatto-Filho, Lucho, Machado \& Vitolo, 1998)
} 
Os grupos trabalham com a finalidade de abrir um espaço social para a reconstrução da cidadania, para o ressignificar do cotidiano, para o fortalecimento do sujeito e o desenvolvimento de sua autodeterminação. A proposição dos Grupos de Ação Solidária compartilha com a concepção de ser humano não como algo pronto, mas como sujeito de relações em contínua construção. Segundo Guareschi (1995), ser humano significa tornar-se humano, conquistar-se como resultado de milhares de relações que estabelece com os outros.

Algumas proposições de Arendt (1997) também sustentam a proposta. A autora, ao eleger a ação como uma prerrogativa exclusiva dos humanos, preconiza sua dependência da presença constante de outros. Busca, na etimologia do verbo agir, as explicações para essa convergência, tanto na origem grega como latina (no latim, agir vem de agire, por em movimento, e de gerere, com o sentido de conduzir). A consciência da mudança das circunstâncias e da atividade humana só pode ser compreendida e racionalmente entendida como prática transformadora, como ação.

Segundo Wagner (2002), interpretando Arendt, a ação como ato em si revela a singularidade de seu ator, sendo esse o motivo pelo qual a ação não existe sem a palavra. $\mathrm{Na}$ ação, o indivíduo, através do discurso, conta "quem ele é", revelando, assim, a sua identidade.

Daí depreende-se que a ação é composta de um começo desencadeado por alguém e de uma realização à qual muitos aderem para conduzir e levar a cabo um determinado empreendimento. Arendt (1997) assinala:

(...) pelo fato de que se movimenta sempre entre e em relação a outros seres atuantes, o ator nunca é simples agente. Mas também, e ao mesmo tempo, paciente. (...) a ação embora possa provir do nada, atua sobre um meio no qual toda a reação se converte em reação em cadeia, e todo o processo é causa de novos processos. Como a ação atua sobre seres humanos que também são capazes de agir, a reação, além de ser uma resposta, é sempre uma nova ação com poder próprio de atingir e afetar os outros (p. 203).

O espaço grupal é um espaço que favorece o estabelecimento de relações e o qualificativo solidariedade que o nomeia remete a essa dependência e responsabilidade mútuas. Assim, os Grupos de Ação Solidária têm o objetivo de se constituírem como um lugar para compartilhar experiências e propor ações de engajamento social. Não se restringem à busca de soluções de problemas individuais, pois se privilegia a proposição de ações coletivas com potencial de transformação social.

O grupo, através da verbalização dos sujeitos e do processo de escuta instaurado nesse espaço, propicia a criação de uma identidade e, através da ação, conquista o produto mais imediato que é a realidade: a realidade do próprio eu, da própria identidade, do mundo circundante. Como refere Wagner (2002), "a ação, com todas suas incertezas, é como uma recordação permanente de que os homens, ainda que tenham de morrer, não nasceram para a morte, senão para começar algo novo. A ação é a própria liberdade" (p. 73). Liberdade para conquistar outros espaços, para construir estratégias de resistência frente às políticas institucionais que os excluem do acesso à saúde e à dignidade.

A Saúde do Trabalhador, como ação estratégica, incorpora esses conceitos quando preceitua que não é possível transformar a realidade sem conhecê-la e que, para conhecê-la, é imprescindível a participação ativa dos trabalhadores. A própria legislação coloca como direitos dos trabalhadores o conhecimento dos riscos e o controle social sobre as ações institucionais e empresariais. O que, por sua vez, coloca o trabalhador como sujeito ativo desse processo a partir de uma concepção que coloca a Saúde do Trabalhador no contraponto do modelo hegemônico vigente (Nardi, 1997). 
Os grupos procuram, ao questionar os pressupostos do adoecimento no trabalho, criar condições para que consciências críticas se desenvolvam, propulsionando ações transformadoras da realidade social. Aí se incluem a superação dos limites da "cegueira" imposta pela ideologização e da alienação dos trabalhadores e a mudança dos ambientes de trabalho, das práticas negativas das instituições que deveriam proteger.

Os grupos são abertos a portadores de LER/DORT a partir de convites dos membros ou de campanhas de divulgação. Reúnem-se semanalmente em espaços como instituições universitárias e órgãos sindicais. Têm uma média de 10 a 15 membros e duração de uma hora e trinta minutos. Têm um coordenador (membro do grupo) e um facilitador (técnico que acompanha o trabalho, médico, psicólogo, assistente social, fisioterapeuta, terapeuta ocupacional ou educador físico). Em geral, o facilitador acompanha todas as reuniões grupais e coordena o chamado de outros profissionais conforme os casos tratados.

A metodologia de trabalho é determinada a partir de um "emergente grupal", conforme expressão cunhada por Pichón-Rivière (1998), que pode ser uma tarefa solidária entre os pares (por exemplo, a disposição de uma alternativa frente a um problema específico de um dos participantes, como o acompanhamento nas perícias médicas) ou o encaminhamento de propostas construídas coletivamente (como programas de conscientização e prevenção de LER/DORT na forma de campanhas publicitárias, páginas na internet, contatos com a imprensa, manifestações, visitas a instituições públicas etc.). A partir do momento em que uma "situação problema" é apresentada, promove-se a sua análise coletiva com base nas experiências e vivências dos membros dos grupos, sistematizando os conhecimentos que podem subsidiar a busca de soluções e a proposição de ações de intervenção. Tal metodologia tem o objetivo de favorecer a integração entre os participantes e desenvolver a criatividade e a consciência crítica.

Segundo Giddens (1982), a consciência é um conceito psicossociológico que se refere aos significados que os indivíduos atribuem às interações diárias e aos acontecimentos de suas vidas. Portanto, não é um mero espelhamento do mundo material, mas a atribuição de significados ao ambiente social que servem como guias de conduta e que são resultados de um exercício contínuo de relação com os outros. A consciência crítica tem o potencial de mobilizar para a ação e de romper com a postura de resignação. Resignação, inclusive, em relação ao convívio constante com a dor; Moore (1978) é um dos autores que alerta para o risco da dor e do sofrimento se tornarem "amenos" pelo hábito, pela continuidade na ingestão de um "veneno", ensejando a passividade e a resignação como posturas de vida.

Embora Arendt (1997) qualifique a dor física como o mais privado dos sentimentos humanos, o trabalho com grupos de portadores de LER/DORT com dor crônica propõe constituir-se em um espaço em que esse sentimento possa ser compartilhado com outros que vivenciam experiências similares. Portanto, os grupos são um espaço que propicia o resgate da esfera pública, dada a sua importância na condição de vida dos humanos. Segundo a mesma autora:

Para o indivíduo, viver uma vida inteiramente privada significa acima de tudo, ser destituído de coisas essenciais à vida verdadeiramente humana: ser privado da realidade que advém do fato de ser visto e ouvido por outros, privado de uma relação "objetiva" com eles. (...) o homem privado não se dá a conhecer, e portanto é como se não existisse. $\mathrm{O}$ que quer que faça permanece sem importância ou conseqüência para os outros e o que tem importância para ele é desprovido de interesse para os outros (p. 68).

O exame, no espaço público, das situações de trabalho associadas ao adoecimento, oportunizado pelo grupo, revela-se como um mobilizador de uma consciência coletiva capaz de sustentar ações conjuntas. Sandoval (1994) é um dos autores que considera o trabalho como ocupando um papel fundamental na formação da consciência de classe; faculta às 
rupturas ocorridas no cotidiano de trabalho a função de propiciar a superação da consciência individual fragmentada. A partir do pressuposto de que o adoecimento é uma ruptura do cotidiano de trabalho, enseja-se a construção de uma consciência coletiva capaz de sustentar ações coletivas de transformação deste cotidiano laboral como uma experiência concreta de cidadania. Fortalecer a cidadania é mais um dos objetivos dos Grupos de Ação Solidária, pois, conforme sugere Cardia (1994), a existência de uma cidadania frágil ignora, por exemplo, o direito à integridade física como uma condição a outros direitos humanos.

Merlo (1999) refere que, frente a uma organização do trabalho desestruturante, a saúde constrói-se, principalmente, a partir de um enfrentamento cotidiano, muitas vezes individual e solitário, mas salienta que o enfrentamento coletivo e consciente é o responsável por modificações na organização e nos ambientes de trabalho, com repercussões perceptíveis sobre a saúde dos trabalhadores. O envolvimento dos participantes se faz através da compreensão do espaço de trabalho como espaço concreto de exploração e a saúde do trabalhador como expressão, igualmente concreta, dessa realidade. O processo de tomada de consciência dos trabalhadores articula-se a partir de vários elementos: a compreensão de que a doença e os acidentes não são acontecimentos fortuitos e individuais, mas sim uma condição da coletividade; a democratização e a responsabilização pelas ações e, com isso, a possibilidade real de lutar e conseguir transformações; a compreensão integral das condições de trabalho, à medida que não é tal ou qual risco que faz adoecer os trabalhadores, mas sim o conjunto dos elementos do processo de trabalho.

A transformação do sujeito só é possível através do avanço da consciência através da ação. Segundo Fromm (1967), é a existência social dos homens que determina sua consciência. A produção de idéias, de conceitos, de consciência é, a princípio, mesclada com a atividade material e as relações materiais dos homens, a linguagem da vida real. A consciência nunca pode ser senão existência consciente e a existência dos homens em seu processo vital real.

Fromm (1967) afirma que não só as circunstâncias fazem o homem, este também faz as circunstâncias. O homem muda no decurso da história, é o produto da história; assim como ele faz a história, ele é seu próprio produto. A história é a história da auto-realização do homem; ela nada mais é que a autocriação do homem por intermédio de seu próprio trabalho e produção.

\section{Algumas propostas concretas empreendidas pelos Grupos de Ação Solidária}

Os vários grupos que se reúnem semanalmente em diferentes espaços geográficos e com o apoio direto do Sindicato dos Bancários de Porto Alegre, IPA (Instituto Porto Alegre), Hospital de Clinicas de Porto Alegre, sindicatos, associações de classe, universidades (UFRGS e PUCRS), propuseram algumas ações e, dentre elas, a de maior relevância foi a criação do Fórum Permanente de Prevenção de LER/DORT. Esse Fórum, em permanente processo de construção e de mediações com a sociedade, reúne representantes dos Grupos de Ação Solidária, Associação dos Portadores de LER, centrais sindicais, sindicatos e associações profissionais, de órgãos governamentais (como Delegacia Regional do Trabalho, Ministério Público Federal e Estadual, Instituto Nacional de Seguridade Social, Secretaria de Saúde do Estado do Rio Grande do Sul, Assembléia Legislativa do Rio Grande do Sul) e tem como objetivos: integrar os diferentes agentes envolvidos com questões relacionadas à LER/DORT; 
socializar as informações sobre a temática, discutir e construir ações conjuntas de diagnóstico, tratamento, reabilitação e prevenção; sensibilizar e intervir sobre os fatores e contextos geradores de LER/DORT; mobilizar a sociedade e os trabalhadores, em particular, para a problemática; dar visibilidade à doença e difundir informações a seu respeito.

Em um ano de funcionamento, o Fórum Permanente de Prevenção de LER/DORT realizou um Encontro Estadual e dois cursos para capacitação e para a criação de outros grupos de monitores, para atuarem junto aos Grupos de Ação Solidária. Outra atividade do Fórum e dos Grupos de Ação Solidária foi a organização de um seminário no III Fórum Social Mundial, com o título "Um mundo sem LER é possível". Esse seminário contou com a participação de representantes de vários países envolvidos com a temática e se constituiu em um espaço de divulgação e de legitimação do trabalho desenvolvido pelos Grupos de Ação Solidária.

Entre outras atividades, tais grupos formalizaram denúncias junto ao Ministério Público, referentes às discriminações a que os portadores de LER/DORT estão submetidos nos locais de trabalho, e junto à Superintendência do INSS, sobre o tratamento dispensado aos portadores nas perícias médicas. Organizaram um ato público no dia oficializado como de combate à LER/DORT no Estado do Rio Grande do Sul (28 de fevereiro), com entrega de uma carta aberta à sociedade e com a apresentação de uma peça de teatro em praça pública denunciando as arbitrariedades a que estão expostos nos locais de trabalho, na assistência médica e, inclusive, nas suas relações familiares. Essas ações se fundamentam na concepção de que a reação dos grupos de excluídos desempenha um papel fundamental, conforme argumenta Cardia (1994); para essa autora, é necessário que esses grupos fortaleçam a participação social e que sejam capazes de aplicar sanções aos grupos dominantes e, ao mesmo tempo, de estabelecer apoios em elementos desses grupos.

Uma ação, proposta por um dos Grupos de Ação Solidária, consistiu na criação de uma cooperativa que agrega portadores de LER/DORT. Essa cooperativa tem o objetivo de favorecer a reinserção produtiva desses trabalhadores e sua reabilitação profissional. Nesse sentido, tais grupos também apresentam um potencial importante no sentido de propiciar um retorno à atividade produtiva, questão fundamental para o resgate da autonomia e da cidadania.

\section{Considerações finais}

Os Grupos de Ação Solidária têm um caráter ativo e mutável, adaptando-se a realidades diferenciadas. A ênfase recai na busca de soluções para tarefas coletivamente estabelecidas para que a reflexão propicie a instauração de novos conhecimentos e novos modos de agir sobre si mesmos e sobre o contexto social. Essa prática tem permitido o desenvolvimento da criatividade e a construção de espaços e laços solidários. A solidariedade apresenta-se como um dispositivo capaz de romper com o individualismo, com a resignação queixosa e é capaz de desenvolver a consciência crítica e de suscitar a proposição de ações de transformação social.

Assim, o papel terapêutico desses grupos tem sido o de promover a redefinição dos comportamentos de dependência e de passividade e de propiciar um exercício contínuo de leitura crítica da realidade social. Essa prática tem permitido a apropriação de um conhecimento coletivamente construído e a aquisição de uma outra postura frente às situações associadas ao adoecimento.

Como todo o trabalho de grupo, apresenta um desenvolvimento descontínuo. São 
comuns situações de crise, abandono por alguns membros e períodos de passividade e de inércia. Mantém-se uma certa dependência de figuras representadas como de posse de um saber "científico" sobre a LER/DORT e a necessidade de que essas figuras funcionem como estimuladoras do grupo. Diante dessa tendência, são estimulados os laços solidários entre os participantes, bem como são valorizados os saberes e as alternativas construídos por eles próprios no decorrer da reflexão sobre o processo de saúde-enfermidade-trabalho. Pois, conforme Arendt (1997), a liberdade não é a liberdade privada da não-interferência, mas sim a liberdade pública de participação democrática.

O objetivo é o direito à saúde e à inclusão social a partir das garantias constitucionais e daquelas pautadas pela Lei Orgânica da Saúde de 1990. Como nos adverte Cassou (1984), a finalidade é a busca incessante de que os trabalhadores ganhem vida e não a percam ao ganhá-la.

\begin{abstract}
A proposal on Worker's Health with workers whit Repetitive Strain Injuries (RSI): Solidary Action Groups

This article describes the development of the Solidary Action Groups. It introduces its characteristics and presuppositions as a Worker's Health intervention identified with social transformation. Solidary Action Groups are more than a complementary resource on the treatment of workers whit Repetitive Strains Injuries (RSI) or Work Related Musculoskeletal Disorders (WRMD). The methodology of work is based on operative groups technic (PichonRivière), so that when a 'problem-situation' is presented by a member of the group, a collective analysis is promoted based on workers' experiences. Then, the acquirements are systemized with the aim to propose solutions and forms of intervention. This methodology has the aim to develop critical consciousness, propitiating the ransom of public space, reconstruction of citizenship, social engajement and construction of solidary relationships. In this manner, these groups promote a redefinition of dependency and passive behaviors and allow the appropriation of collective acquirements, as well as the acquisition of a different attitude related to work sickness.
\end{abstract}

Keywords: "Joint action" groups, Repetitive Strain Injuries, Work Related Musculoskeletal Disorders, Worker's Health.

Endereços para contato com as autoras:

Maria da Graça Hoefel: gracahof@portoweb.com.br

Maria da Graça Jacques: fjacques@terra.com.br

Mayte Raya Amazarray: maytepsi@hotmail.com

Jussara Rosa Mendes: jussara@plug-in.com.br

Jacéia Aguilar Netz: jaceia@bancariospoa.com.br

Manuscrito recebido em: 22/09/2003

Envio de pareceres às autoras: 30/10/2003

Aprovado para publicação em: 11/11/2003 


\section{Referências bibliográficas}

Arendt, H. (1997). A condição humana. (8a ed.). Rio de Janeiro: Forense Universitária.

Cassou, B. (1984). Les risques du travail: pour ne pás perdre as vie à la gagner. Paris: La Découverte.

Cardia, N. (1994). Percepção dos direitos humanos: ausência de cidadania e a exclusão moral. In M. J. P. Spink (Org.), A cidadania em construção (pp. 15-58). São Paulo: Cortez.

Fromm, E. (1967). Conceito marxista do homem. Rio de Janeiro: Zahar.

Giddens, A. (1982). Class structuration and class consciousness. In A. Giddens \& D. Held (Orgs.), Classes, power and conflict (pp. 157-174). Berkeley: University of California Press.

Giddens, A. (2002). Modernidade e identidade. Rio de Janeiro: Zahar.

Guareschi, P. (1995). Ética e relações sociais. In M. G. Jacques, M. L. Nunes, N. Bernardes \& P. Guareschi (Orgs.), Relações sociais $\mathfrak{E}$ ética (pp. 13-18). Porto Alegre: ABRAPSO Regional Sul.

Hoefel, M. G., Mérola, S. \& Bianchesi, D. (2003). Grupos com portadores de LER/DORT: uma construção coletiva do processo de reabilitação profissional. In R. C. Ruiz (Org.), Um mundo sem LER é possivel (pp. 110-136). Montevidéo: Rel/UITA.

Lima, A. B. \& Oliveira, F. (1995). Abordagem psicossocial da LER: ideologia da culpabilização e grupos de qualidade de vida. In W. Codo \& M. C. C. G. Almeida (Orgs.), LER: diagnóstico, tratamento e prevenção - uma abordagem interdisciplinar (pp. 136-162). Petrópolis: Vozes.

Luzzato-Filho, D., Lucho, M. A., Machado, P. P. \& Vitolo, U. (1998). Uma abordagem socioeconômica do Fenômeno LER/DORT em População de Bancários de Porto Alegre. Trabalho de Conclusão de Curso, Curso de Especialização em Medicina do Trabalho, Universidade Federal do Rio Grande do Sul, Porto Alegre.

Maeno, M. (2003). As lesões por esforços repetitivos (LER). Distúrbios osteomusculares relacionados ao trabalho (DORT). In R. C. Ruiz (Org.), Um mundo sem LER é possível (pp. 81-110). Montevidéo: Rel/UITA.

Merlo, A., Jacques, M. G. \& Hoefel, M. G. (2001). Trabalho de grupo com portadores de LER/DORT: relato de experiência. Psicologia, Reflexão e Crítica, 14 (1), 253-258.

Merlo, A., Jacques, M. G. \& Hoefel, M. G. (1999). A Informática no Brasil: prazer e sofrimento no trabalho. Porto Alegre: UFRGS.

Ministério da Saúde (2001). Doenças relacionadas ao trabalho. Manual de procedimentos para os serviços de saúde. Brasília: Ministério da Saúde.

Moore, B. (1987). Injustice: the social bases of obdience and revolt. Nova Iorque: Sharp.

Nardi, H. (1997). Saúde do trabalhador. In A. Cattani (Org.), Trabalho e tecnologia: dicionário crítico (pp. 219-224). Petrópolis: Vozes.

Pichon-Rivière, E. (1998). O processo grupal (6⿳丷ㄹ. ed.) São Paulo: Martins Fontes.

Ruiz, R. C. (2003) Idéias iniciais. In R. C. Ruiz (Org.), Um mundo sem LER é possível (pp. 9-58). Montevidéo: Rel/UITA.

Sandoval, S. Algumas reflexões sobre cidadania e formação de consciência política no Brasil. In M. J. P. Spink (Org.), A cidadania em construção (pp. 59-74). São Paulo: Cortez.

Sato, L., Araújo, M., Udihara, M. L., Franco, M. A., Nicotera, F., Daldon, M. T. Settimi, M. M. \& Silvestre, M. (1993). Atividades em grupo com portadores de LER e achados sobre a dimensão psicossocial. Revista Brasileira de Saúde Ocupacional, 79 (21), 49-71.

Wagner, E. S. (2002). Hannah Arendt $\mathcal{E}$ Karl Marx: o mundo do trabalho. São Paulo: Ateliê. 